\title{
The Significance of Basal Insulin Levels in the Evaluation of the Insulin Response to Glucose in Diabetic and Nondiabetic Subjects *
}

\author{
John D. Bagdade, $\ddagger$ Edwin L. Bierman, $\S$ and Daniel Porte, Jr.\| \\ (From the Department of Medicine, University of Washington School of Medicine, and the \\ Veterans Administration Hospital, Seattle, Washington)
}

\begin{abstract}
The level of insulin after an overnight fast (basal) in 37 obese and nonobese male subjects with normal and abnormal carbohydrate tolerance was directly related to the increase in insulin concentration during a $3 \mathrm{hr} 100 \mathrm{~g}$ oral glucose tolerance test. Obesity, but not diabetes, was associated with an elevation of this basal insulin level. Thus obesity predicted with the magnitude of the insulin response to glucose ingestion. When the individual insulin values were expressed as per cent change from the basal level, this effect of obesity was excluded. The insulin levels of all subjects with normal carbohydrate tolerance promptly rose 5-7-fold, and reached peak values $1 \mathrm{hr}$ after oral glucose. In contrast, the diabetic response (as per cent increase) was markedly reduced during the $1 \mathrm{st} \mathrm{hr}$, and maximal (but still subnormal) insulin levels were not attained until $2 \mathrm{hr}$. In all subjects the insulin response (quantitated by calculation of the area circumscribed by a plot of the per cent change in insulin with time) showed a significant inverse correlation with the glucose response. Thus increasing degrees of carbohydrate intolerance were associated with decreasing insulin responses. Elevated levels of insulin, in both the basal state and in response to glucose, were related to obesity.
\end{abstract}

\section{$\mapsto$ \\ Introduction}

When the first measurements of serum immunoreactive insulin levels were made during oral glucose tolerance tests (1), mild diabetics were ob-

* Received for publication 17 March 1967 and in revised form 9 June 1967.

Supported in part by U. S. Public Health Service Grant AM-06670. A portion of this work was conducted through the Clinical Research Center facility of the University of Washington (NIH Grant FR-37). Presented in part at the 20th Annual Meeting of the Western Society for Clinical Research, Carmel, Calif., 26 January 1967. (1967. Clin. Res. 15 : 137).

$\ddagger$ Assistant in Medicine, University of Washington School of Medicine; Postdoctoral Research Fellow, National Institutes of Health.

§ Associate Professor of Medicine, University of Washington School of Medicine; Chief, Metabolic Disease Service, VA Hospital, Seattle; Career Development Awardee, 5K3 AM-28, 167, National Institutes of Health.

II Assistant Professor of Medicine, University of Washington School of Medicine; Clinical Investigator, VA Hospital, Seattle. served to achieve higher insulin levels than subjects with normal glucose tolerance. Subsequently it was found that this exaggerated insulin response to glucose was not solely a feature of mild diabetes, but also occurred in obese nondiabetic subjects (2). The observation that weight reduction restored normal carbohydrate tolerance, and abolished the excessive insulin response to glucose in one obese, mildly diabetic subject, suggested that obesity may contribute to the high insulin levels found in mild diabetes (3).

Since most adult-onset diabetics are obese, the effect of obesity on insulin regulatory mechanisms must be carefully defined before insulin responses in diabetes can be properly evaluated. The present study was undertaken to separate the effects of obesity and diabetes on serum insulin responses to glucose.

Address requests for reprints to Dr. John Bagdade, Veterans Administration Hospital, 4435 Beacon Avenue South, Seattle, Wash. 98108. 


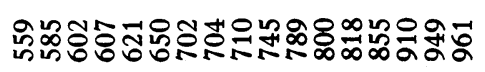

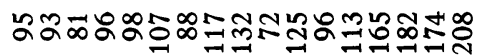

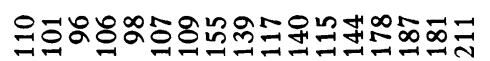

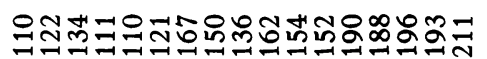

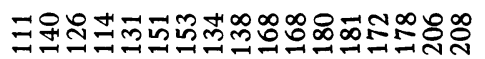

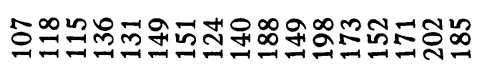

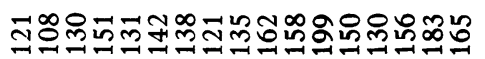

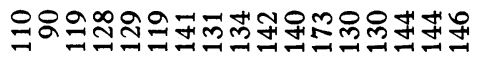

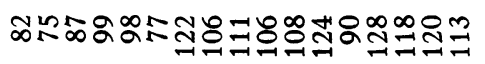

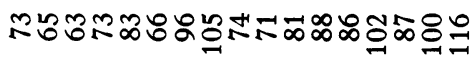

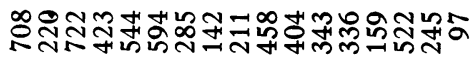

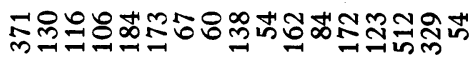

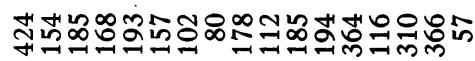

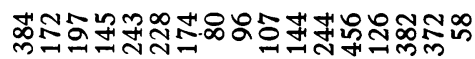

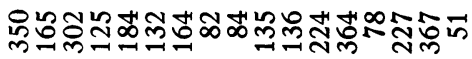

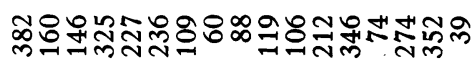

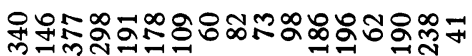

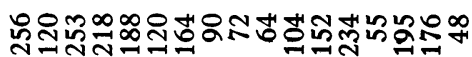

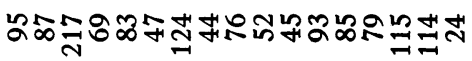

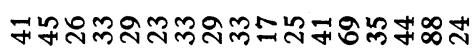

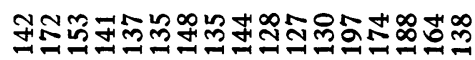

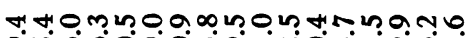

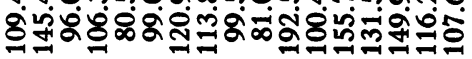

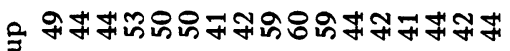

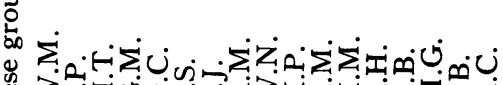

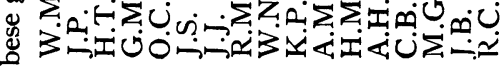




\section{Methods}

37 (17 obese and 20 nonobese) ambulatory, apparently healthy male volunteers, aged 40 to 60 , were studied. Of these, 34 subjects were hospitalized on a metabolic ward for 3 days before the study, and fed a weight-maintaining diet which contained $300 \mathrm{~g}$ of carbohydrate daily. The additional three subjects were hospital employees who received the same dietary preparation, but were not hospitalized. Seven subjects had previous evidence of carbohydrate intolerance and were receiving oral hypoglycemic treatment which was discontinued at least $1 \mathrm{wk}$ before hospitalization for study. No subject had ever received insulin treatment. All subjects who weighed in excess of $25 \%$ of ideal body weight by Metropolitan Life Insurance Company tables were classified as obese; subjects who were within $15 \%$ of ideal body weight as nonobese.

After 3 days of dietary preparation in the hospital, 3-hr oral glucose tolerance tests ( $100 \mathrm{~g}$ glucose solution) were performed on all subjects at bed rest after an overnight fast. Two, and in most cases three blood specimens were obtained in the basal state via an indwelling needle before glucose ingestion. Additional blood samples were obtained at $15,30,45,60,90,120,150$, and $180 \mathrm{~min}$ after glucose ingestion. Blood glucose was measured by glucose oxidase (4) and serum immunoreactive insulin (IRI) determined in duplicate by a modification of the double antibody technique of Morgan and Lazarow (5). In a representative assay, determination of the precision of replicate analysis (6) for 40 random unknowns yielded a coefficient of variation of $9.1 \%$. At the conclusion of this study, one fasting serum sample from each subject was reanalyzed for insulin. The mean of these fasting samples wăs unchanged in the second assay. The coefficient of variation of these fasting insulin pairs determined in separate assays was $18 \%$.

The mean area circumscribed by the blood glucose time curve was determined in duplicate by planimetry (glucose response), expressed in arbitrary units, and used as an index of glucose tolerance. This method quantitates the normal phenomenon of multiple blood glucose peaks, and therefore more closely reflects the total response to glucose ingestion (7). The insulin responses closely paralleled the changes in blood glucose, including the presence of more than one peak, and were also measured by planimetry and expressed in arbitrary units. To separate clearly normal from abnormal carbohydrate tolerance, we arbitrarily employed the mean glucose response of 10 normal nonobese subjects with no family history of diabetes as an index of normal glucose tolerance for all 37 subjects. Glucose responses that fell within one standard deviation of the mean response of the normal group were considered normal $(n=14)$, those between one and two standard deviations above the mean normal were considered "border-line" $(n=10)$, and those greater than two standard deviations above mean normal were considered diabetic $(n=13)$. The borderline subjects were excluded when the normal and diabetic insulin responses were separated and compared. However, all linear correlations include the responses of the entire group of 37 subjects. All data were punched on standard IBM cards and linear correlations determined by the use of BMD biomedical computer programs and the 7094 IBM computer (8). Areas were also determined by computer calculation (PDP 8) and agreed closely with those measured by planimetry.

\section{Results}

Fasting insulin levels of obese subjects $(36 \mu \mathrm{U}$ \pm 17.6 ; mean $\pm \mathrm{SD})$ were significantly higher $(P<0.001)$ than those of the thin subjects $(15$ $\mu \mathrm{U} \pm 4.8$ ) (Table I). In the entire group of subjects, fasting IRI correlated directly with ideal body weight (Fig. 1, $r=0.72, P<0.001$ ), but not with glucose intolerance (Table II, $r=0.25$,

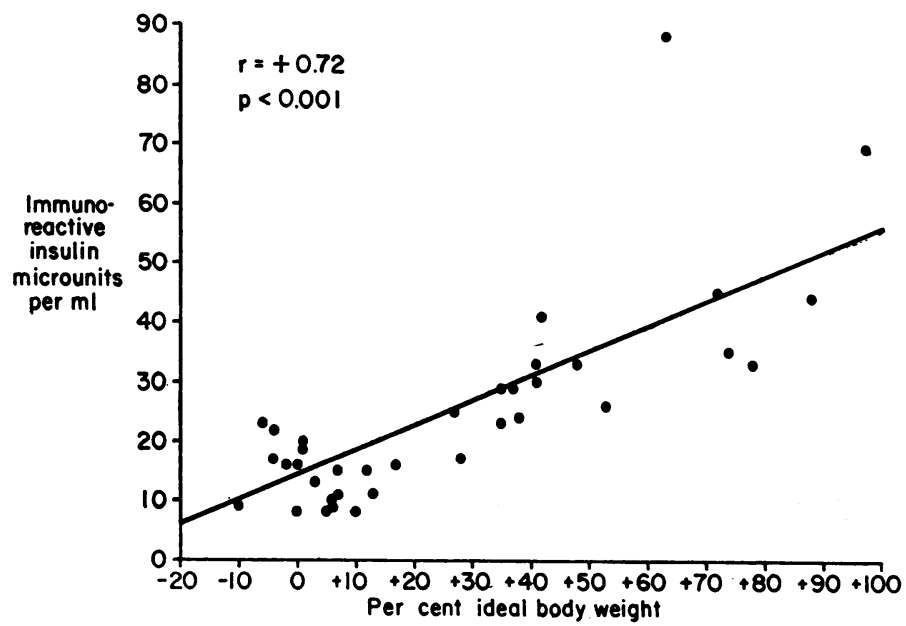

Fig. 1. CoRrelation OF FASTING SERUM IMMUNOREACTIVE INSULIN AND OBESITY EXPRESSED AS PER CENT OF IDEAL BODY WEIGHT. 
TABLE II

Correlation between insulin and glucose responses*

\begin{tabular}{|c|c|c|c|c|c|c|c|c|}
\hline & \multirow{2}{*}{$\begin{array}{c}\text { Body } \\
\text { weight } \\
\% \text { ideal }\end{array}$} & \multirow[b]{2}{*}{$\begin{array}{c}\text { Fasting } \\
\text { IRI }\end{array}$} & \multirow{2}{*}{$\begin{array}{c}\text { Fasting } \\
\text { blood } \\
\text { glucose }\end{array}$} & \multirow[b]{2}{*}{$\begin{array}{l}\text { Glucose } \\
\text { response }\end{array}$} & \multicolumn{4}{|c|}{ Insulin responses } \\
\hline & & & & & $\begin{array}{c}180 \text { min } \\
\text { per cent }\end{array}$ & $\begin{array}{l}60 \text { min } \\
\text { per cent }\end{array}$ & $\begin{array}{l}180 \min \\
\text { absolute }\end{array}$ & $\begin{array}{c}60 \min \\
\text { absolute }\end{array}$ \\
\hline Body weight, $\%$ ideal & & 0.72 & NS & NS & NS & NS & 0.62 & 0.53 \\
\hline Fasting IRI & 0.72 & & NS & NS & NS & NS & 0.79 & 0.65 \\
\hline Fasting blood glucose & NS & NS & & 0.86 & -0.45 & -0.55 & NS & NS \\
\hline Glucose response & NS & NS & 0.86 & & -0.40 & -0.58 & NS & NS \\
\hline $\begin{array}{l}180 \min \text { IRI response } \\
\text { (per cent) }\end{array}$ & NS & NS & NS & -0.40 & & 0.61 & 0.51 & 0.60 \\
\hline $\begin{array}{l}60 \text { min IRI response } \\
\text { (per cent) }\end{array}$ & NS & NS & -0.55 & -0.58 & 0.61 & & NS & 0.68 \\
\hline $\begin{array}{l}180 \min \text { IRI response } \\
\text { (absolute) }\end{array}$ & 0.62 & 0.79 & NS & NS & 0.51 & NS & & 0.85 \\
\hline $\begin{array}{l}60 \text { min IRI response } \\
\text { (absolute) }\end{array}$ & 0.53 & 0.65 & NS & NS & 0.60 & 0.68 & 0.85 & \\
\hline
\end{tabular}

IRI, immunoreactive insulin.

${ }^{*} r$ values are indicated where $P<0.05 ; \mathrm{NS}=P>0.05$.

$P>0.5)$. Thus the degree of obesity, and not carbohydrate tolerance, was associated with the insulin level maintained after an overnight fast.

Insulin responses could not be evaluated without consideration of these fasting levels, since there was a highly significant linear correlation be- tween fasting insulin and insulin response to glucose in both nondiabetic and diabetic subjects (Fig. 2). This indicates a tendency for subjects with higher fasting levels to demonstrate greater insulin responses to glucose. Of all measured variables, only obesity was associated with ele-

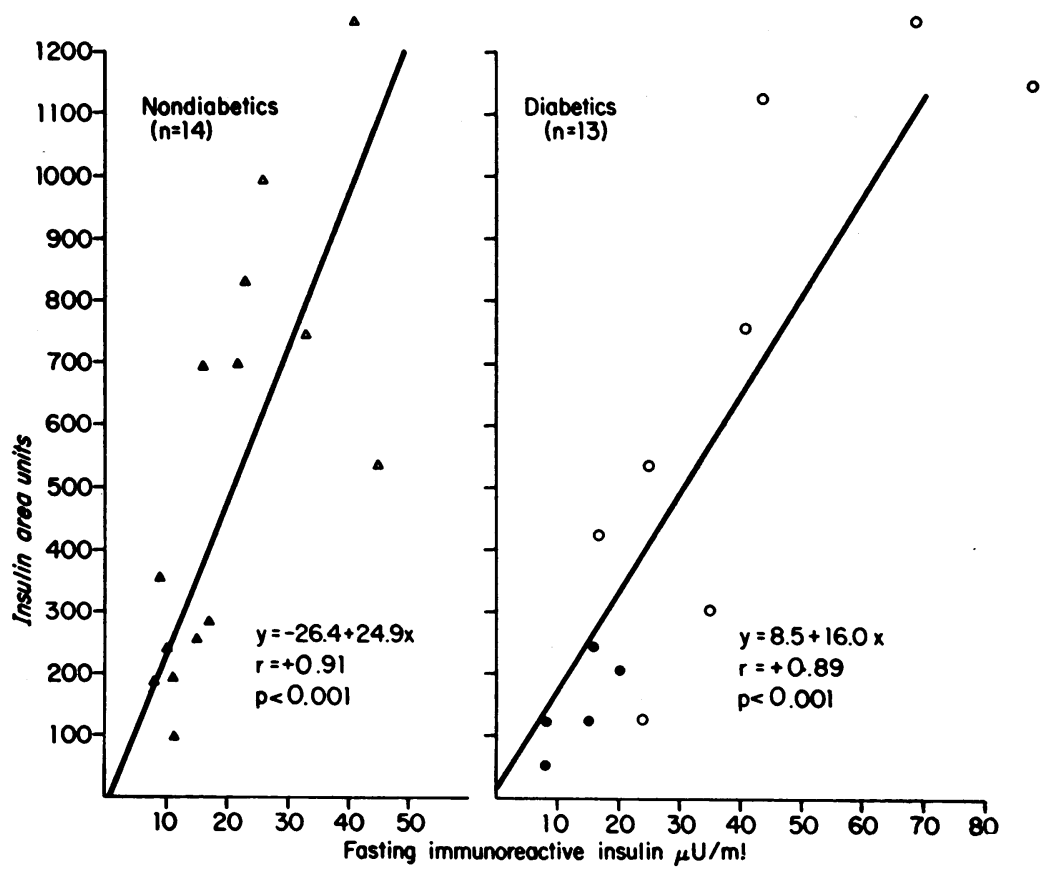

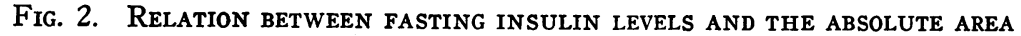
INCREMENT IN PLASMa INSULIN (TOTAL AREA MINUS FASTING AREA) IN THIN $(\Delta, \bigcirc)$ AND OBESE $(\triangle, \bigcirc)$ NONDIABETIC AND DIABETIC SUBJECTS DURING 3-HR ORAL (100 G) GLUCOSE TOLERANCE TESTS. 


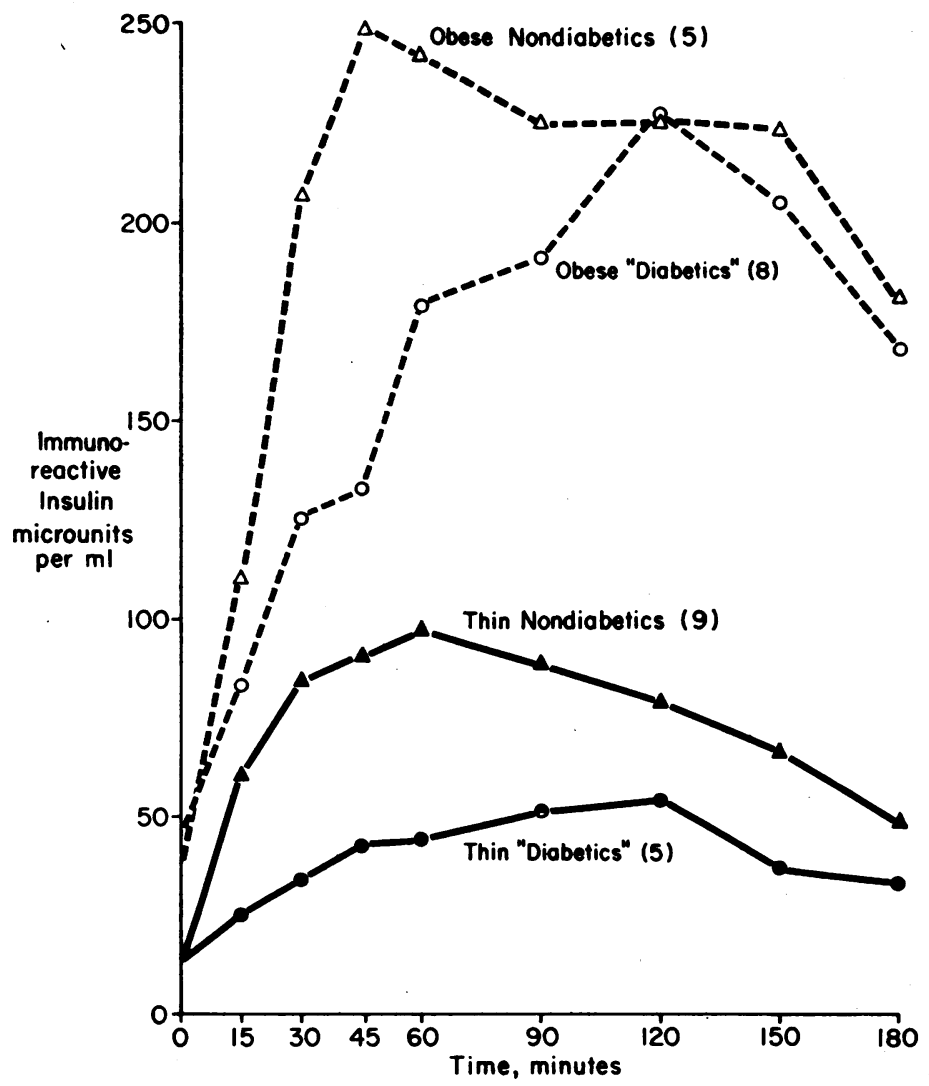

Fig. 3. The MEAN absolute INSUlin RESPonses in thin aND OBESE NONDIABETIC AND DIABETIC SUBJECTS DURING 3-HR (100 G) ORAL GLUCOSE TOLERANCE TESTS.

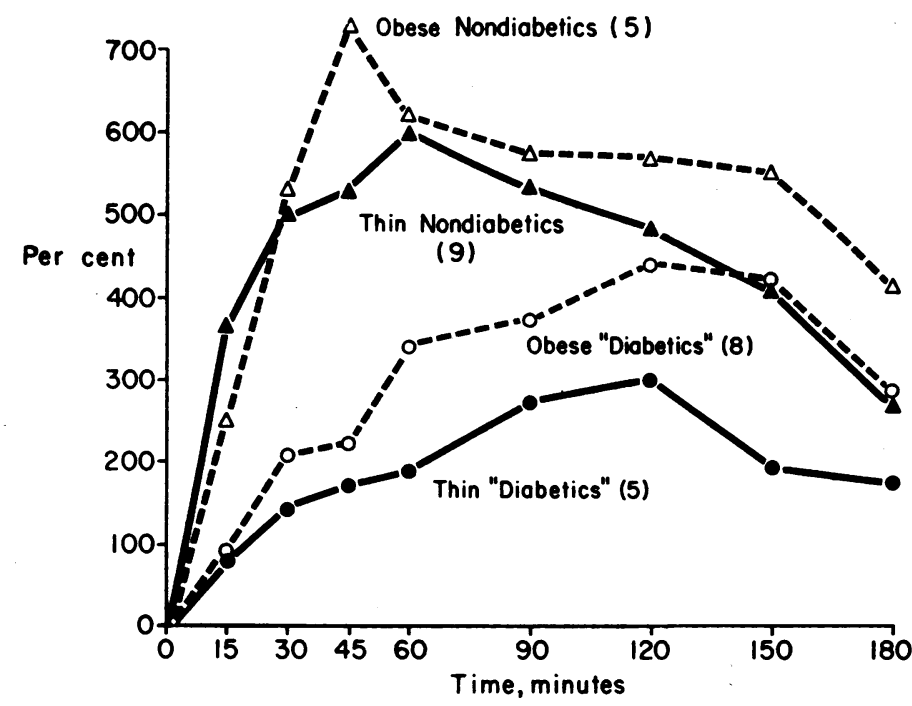

Fig. 4. INSULIN RESPONSES OF THIN AND OBESE NONDIABETIC AND DIABETIC SUBJECTS DURING 3-HR (100 G) ORAL GLUCOSE TOLERANCE TESTS EXPRESSED AS MEAN PER CENT INCREMENTS ABOVE FASTING LEVELS. 
vated fasting insulin levels, and the insulin response to glucose was increased in both groups of obese subjects (Fig. 3).

This effect of obesity on insulin levels had to be eliminated to determine the relation between carbohydrate intolerance and insulin response. Two methods were tested. Responses were expressed as either a per cent change or an absolute increment above the fasting level. Only expression of the response as per cent changes $(r=-0.04, P>$ 1.0) and not absolute increments $(r=0.58, P<$ 0.001 ) eliminated the correlation between obesity and insulin response.

When the insulin responses of all subjects were expressed in this way, thin and obese subjects with normal carbohydrate tolerance sustained a 5-7-fold elevation of circulating IRI levels within 60 min after glucose ingestion (Fig. 4). In contrast, diabetics did not achieve an early insulin peak, but reached maximum insulin levels at $2 \mathrm{hr}$. The insulin responses of the two nondiabetic groups were not significantly different from each other, and therefore the responses were averaged (Fig. 5). Similarly, the IRI responses of the two diabetic groups were not different, and also were averaged. When the nondiabetic and diabetic responses were grouped in this way, insulin responses were significantly decreased in diabetics at 15, 30, $45(P<0.001), 60(P<0.01)$, and 90 min $(P<0.05)$, but did not differ after $90 \mathrm{~min}$. The area circumscribed by the $180 \mathrm{~min}$ integrated per cent insulin curve also was reduced in the diabetic subjects $(P<0.05)$. Thus the total insulin response to glucose was reduced in diabetes, and

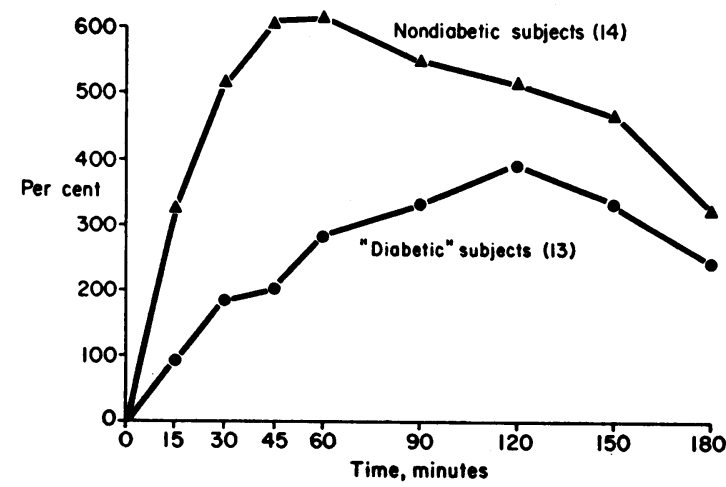

Fig. 5. INSULIN RESPONSES OF NONDIABETIC AND DIABETIC SUBJECTS EXPRESSED AS PER CENT CHANGES FROM FASTING LEVELS DURING 3-HR (100 G) ORAL GLUCOSE TOLERANCE TESTS. this impairment was most marked during the initial 90 min after glucose ingestion.

This early impairment of insulin response to glucose in diabetes is emphasized by the highly significant inverse correlation of the glucose area and the $60 \mathrm{~min}$ integrated per cent insulin response in the entire group of 37 subjects (Fig. $6 \mathrm{~A}, r=$ $-0.63, P<0.001)$. However, a significant inverse correlation $(r=-0.46, P<0.01)$ was still present when the glucose and 180 min integrated per cent insulin responses were compared (Fig. $6 \mathrm{~B})$. The assumption of a linear correlation was not necessary in this analysis, since the nonparametric rank-difference correlation test also showed a significant inverse correlation $(r=-0.41, P<$ $0.02)$. Thus, progressively severe glucose intolerance appeared to be associated with decreasing insulin responses to glucose.

\section{Discussion}

The elevation of basal (fasting) insulin levels found in obese subjects is in accord with other recent observations (9-13). Since no prior attempts appear to have been made to correlate the fasting insulin level with the insulin response, the possibility that the fasting level might predict insulin responses has not been previously considered. Results in the present study show that insulin responses clearly are related to the fasting level.

The significant correlation of the degree of obesity and fasting insulin levels is extremely important, since some studies appear to indicate a relation between fasting insulin levels and diabetes $(11,12)$. However, when subjects with a wide range of glucose tolerance and body weight are examined, as in this study, only obesity and not carbohydrate intolerance is associated with elevated fasting insulin levels.

Although absolute insulin levels are probably important to peripheral tissues, they appear to be a poor index of the adequacy of an insulin response to a glucose stimulus. The relative increment above fasting levels and not the absolute level of circulating insulin appears to distinguish insulin responses in subjects with normal carbohydrate tolerance from insulin responses in subjects with abnormal carbohydrate tolerance. Thus when alterations in serum insulin levels are expressed as relative changes from the basal level, 


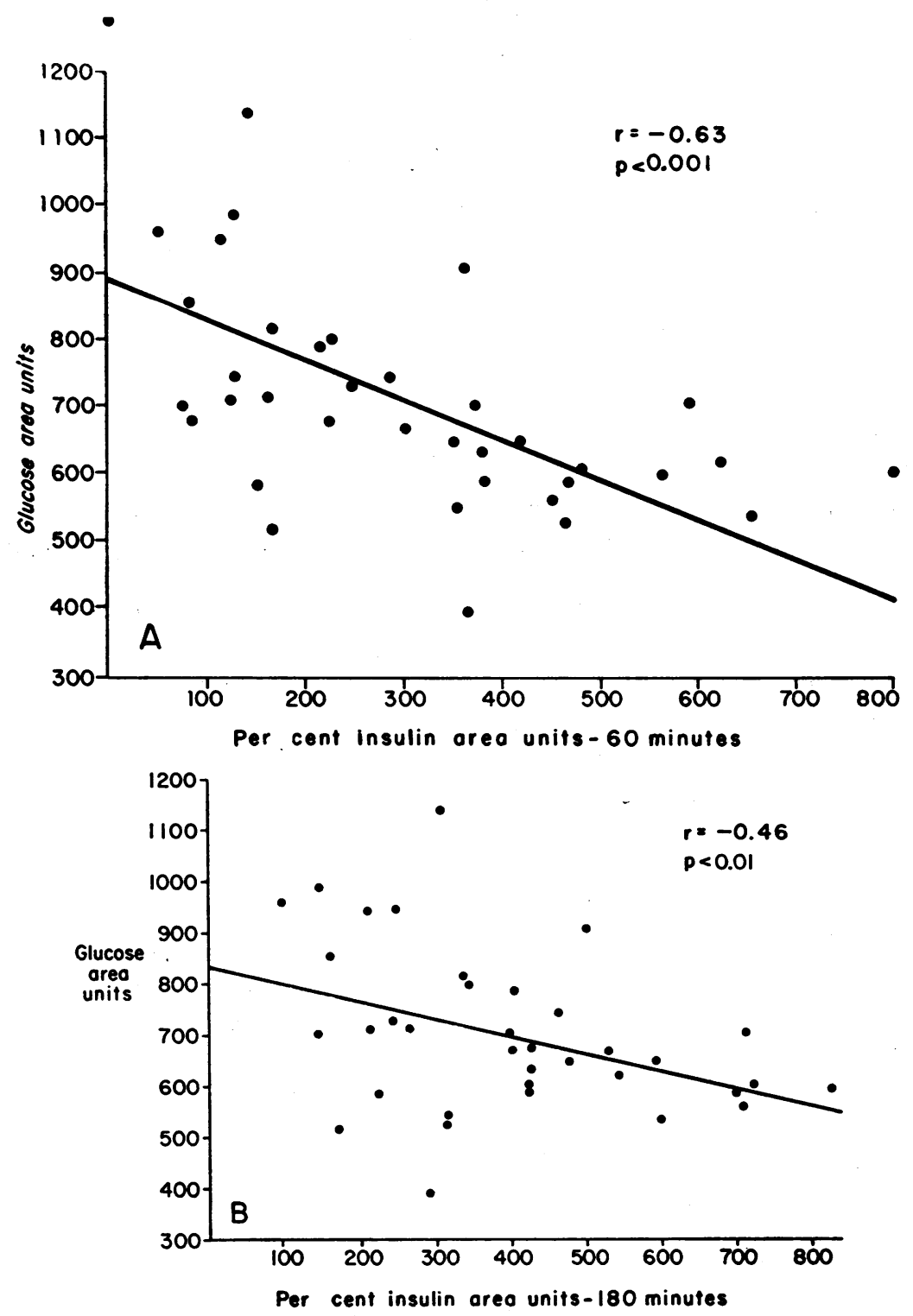

Fig. 6 A and B. Relation between glucose tolerance and the (A) 60 and THE (B) 180 MIN INTEGRATED PER CENT INSULIN RESPONSE IN OBESE AND THIN NONDIABETIC AND DIABETIC SUBJECTS $(n=37)$.

both obese and thin nondiabetic subjects respond similarly.

Adiposity could theoretically influence both fasting insulin levels and the insulin levels in response to glucose by increasing tissue insulin requirements. In accord with this hypothesis, insulin sensitivity of human adipose tissue is diminished in obesity, both in the intact forearm preparation (9) and in isolated adipose cells (14). The observation that weight reduction results in both decreased insulin responses to glucose (3) and a decreased insulin requirement in diabetics further suggests that an increase in adipose tissue mass may impose a greater demand for insulin. If basal insulin levels influence the insulin response to glucose, then a diabetic insulin response may be greater than normal if this diabetic group includes subjects with higher basal insulin levels. The comparison of responses of groups of subjects with differing basal insulin levels may 
explain the findings of elevated insulin levels in diabetes in several recent reports.

For example, a study of insulin levels in obesity (12) was interpreted to show that obese diabetics have greater insulin responses to glucose than obese nondiabetic subjects. Since the diabetic group had a higher mean fasting insulin level, the groups may not have been strictly comparable.

In another study (11) in which insulin levels in obese nondiabetic and diabetic subjects with identical mean fasting insulin levels were compared, the insulin response to glucose was reduced in the diabetic group. In contrast, in this same study the insulin response of the thin diabetic group appeared to be greater than normal. Since the mean fasting insulin level of the thin diabetic group was nearly twice that of the normal group, results of the present study would predict a greater insulin response.

In this study, obesity was the only factor which correlated with the fasting insulin level. It is clear, however, that per cent ideal body weight, which was employed to quantitate obesity, is a poor index of relative adiposity. Other factors, as yet unidentified, probably also influence basal insulin. In the present study two subjects with identical relative weights do not always have identical fasting insulin levels. Only when the group is examined as a whole does the relation between adiposity and basal insulin become evident. However a variation in insulin response related to differences in basal insulin, regardless of the cause, may be eliminated by normalization of the response.

Additional evidence has accumulated which supports the concept of impairment of insulin responses to a variety of stimuli in all diabetics, irrespective of weight. Insulin responses in mild diabetics have been found to be subnormal after the administration of both intravenous (15) and oral glucose $(16,17)$, a mixture of amino acids or arginine (17), and glucagon (18).

Although Yalow and Berson $(19,20)$ and Seltzer et al. (13) also noted a deficient early insulin response and late insulin peak in diabetes, some groups of mild diabetics in their series had greater than normal mean insulin responses to glucose independent of obesity. It is difficult to reconcile these results with the present observations. Differences in dietary preparation and pa- tient selection may contribute to this apparent discrepancy.

If obesity is characterized by hyperinsulinism and carbohydrate intolerance by an insufficient insulin response, why do impaired carbohydrate tolerance and obesity so frequently coexist? Increased tissue demands for insulin in obesity appear to require a high output state of insulin release. If insulin secretory capacity is limited, the added stress on beta-cell reserve imposed by obesity may result in abnormal carbohydrate tolerance, even in the presence of elevated insulin levels.

\section{Acknowledgments}

We appreciate the assistance of Dr. Edward Perrin. Associate Professor of Preventive Medicine and Head Biostatistics Division, who suggested regression analysis as a test of the validity of the use of per cent changes rather than absolute values.

The skilled technical assistance of Julianne Carlin, Suzy Keeler, Martha Kimura, Martha McLean, Susan Page, and Eileen Severns, and the assistance of Raymond Reiser in computer programming are also appreciated.

\section{References}

1. Yalow, R. S., and S. A. Berson. 1960. Immunoassay of endogenous plasma insulin in man. J. Clin. Invest. 39: 1157.

2. Karam, J. H., G. M. Grodsky, and P. H. Forsham. 1963. Excessive insulin response to glucose in obese subjects as measured by immunochemical assay. Diabetes. $12: 197$.

3. Karam, J. H., G. M. Grodsky, F. C. Pavlatos, and P. H. Forsham. 1965. Critical factors in excessive serum-insulin response to glucose. Lancet. 1 : 286.

4. Huggett, A. St. G., and D. A. Nixon. 1957. Use of glucose oxidase, peroxidase and o-dianisidine in determination of blood and urinary gluose. Lancet. 2: 368.

5. Morgan, C. R., and A. Lazarow. 1963. Immunoassay of insulin: two antibody system: plasma insulin levels of normal, subdiabetic, and diabetic rats. Diabetes. 12 : 115.

6. Youden, W. J. 1951. Statistical Methods for Chemists. John Wiley \& Sons Inc., New York. 16.

7. Burns, T. W., R. Bregant, H. J. Van Peenan, and T. E. Hood. 1965. Evaluation of the oral glucose tolerance test by a continuous sampling technique. J. Lab. Clin. Med. $65: 927$.

8. 1965. BMD: Biomedical Computer Programs. W. J. Dixon, editor. Health Sciences Computing Facility. University of California, Los Angeles.

9. Rabinowitz, D., and K. L. Zierler. 1962. Forearm metabolism in obesity and its response to intra- 
arterial insulin. Characterization of insulin resistance and evidence for adaptive hyperinsulinism. J. Clin. Invest. $41: 2173$.

10. Karam, J. H., G. M. Grodsky, and P. H. Forsham. 1965. The relationship of obesity and growth hormone to serum insulin levels. Ann. N. Y. Acad. Sci. $131: 374$.

11. Perley, M., and D. M. Kipnis. 1966. Plasma insulin responses to glucose and tolbutamide of normal weight and obese diabetic and nondiabetic subjects. Diabetes. 15: 867.

12. Kreisberg, R. A., B. R. Boshell, J. DiPlacido, and R. F. Roddam. 1967. Insulin secretion in obesity. New Engl. J. Med. 276, 314.

13. Seltzer, H. S., E. W. Allen, A. L. Herron, Jr., and M. T. Brennan. 1967. Insulin secretion in response to glycemic stimulus: relation of delayed initial release to carbohydrate intolerance in mild diabetes mellitus. J. Clin. Invest. $46: 323$.

14. Salans, L. B., J. L. Knittle, and J. Hirsch. 1967. The role of adipose cell enlargement in the carbohydrate intolerance of human obesity. J. Clin. Invest. $46: 1112$. (Abstr.)
15. Cerasi, E., and R. Luft. 1963. Plasma insulin response to sustained hyperglycemia induced by glucose infusion in human subjects. Lancet. 2 : 1359.

16. Sheldon, J., K. W. Taylor, and J. Anderson. 1966. The effects of long-term acetohexamide treatment on pancreatic islet cell function in maturity-onset diabetes. Metab. Clin. Exptl. 1966, 15 : 874.

17. Floyd, J. C., Jr., E. S. Fajans, C. Thiffault, R. F. Knopf, E. Guntsche, and J. W. Conn. 1966. Subnormal amino acid induced insulin secretion in diabetes mellitus. Clin. Res. 15: 280.

18. Simpson, R. G., A. Benedetti, G. M. Grodsky, J. H. Karam, and P. H. Forsham. 1966. Preliminary report: Stimulation of insulin release by glucagon in - noninsulin-dependent diabetics. Metab. Clin. Exptl. 15 : 1046.

19. Yalow, R. S., S. M. Glick, J. Roth, and S. A. Berson. 1965. Plasma insulin and growth hormone levels in obesity and diabetes. Ann. N.Y. Acad. Sci. $131: 357$.

20. Berson, S. A., and R. S. Yalow. 1965. Some current controversies in diabetes research. Diabetes. $14: 549$. 